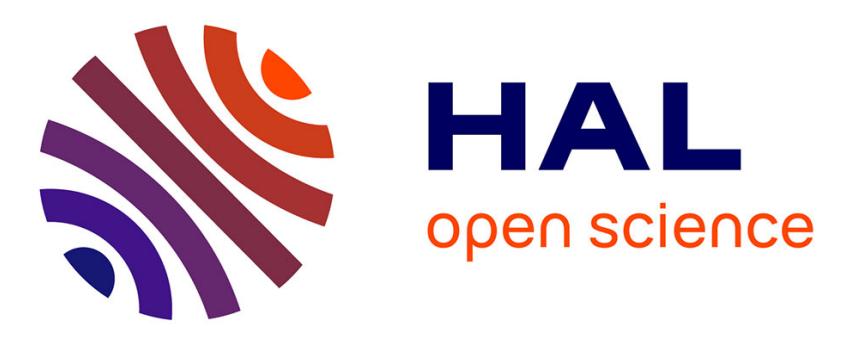

\title{
Fission products behaviour during a power transient: Their inventory in an intragranular bubble
}

Lionel Desgranges, Thierry Blay, J. Lamontagne, Ingrid Roure, Philippe Bienvenu

\section{- To cite this version:}

Lionel Desgranges, Thierry Blay, J. Lamontagne, Ingrid Roure, Philippe Bienvenu. Fission products behaviour during a power transient: Their inventory in an intragranular bubble. Journal of Nuclear Materials, 2017, 493, pp.225-229. 10.1016/j.jnucmat.2017.05.021 · cea-02389213

\section{HAL Id: cea-02389213 https://hal-cea.archives-ouvertes.fr/cea-02389213}

Submitted on 2 Dec 2019

HAL is a multi-disciplinary open access archive for the deposit and dissemination of scientific research documents, whether they are published or not. The documents may come from teaching and research institutions in France or abroad, or from public or private research centers.
L'archive ouverte pluridisciplinaire HAL, est destinée au dépôt et à la diffusion de documents scientifiques de niveau recherche, publiés ou non, émanant des établissements d'enseignement et de recherche français ou étrangers, des laboratoires publics ou privés. 


\title{
Fission products behaviour during a power transient:
}

\section{Their inventory in an intragranular bubble.}

\author{
L.Desgranges, Th. Blay, J. Lamontagne \\ CEA-DEN-DEC 13108 Saint Paul lez Durance, France
}

\begin{abstract}
The behavior of fission products is a key issue during incidental or accidental sequence for nuclear fuel. Here we characterized how fission products behaved inside a $\mathrm{UO}_{2}$ pellet during a power ramp. In the pellet center fission products have left the $\mathrm{UO}_{2}$ ceramic and can be found in bubbles. The composition of the bubble was determined using an original experimental methodology. The existence of separated precipitates made of metallic, for the one, and volatile, for the other, fission products was evidenced. This result is discussed with regards to the behavior of fission products during a power ramp.
\end{abstract}

\section{Introduction}

The behaviour of volatile fission product is key factor when nuclear fuel undergoes an incidental or accidental sequence. The amount of volatile fission products and the associated chemical phases are the primary source term for the chemically induced failure of cladding and the dispersion of radionuclides out of fuel element (see for example [']). In a previous paper we evidenced that the release of volatile fission products, under a chemically aggressive form, could be observed in a fuel element that has been submitted to a power ramp [i]]. Coupled thermomechanical and thermodynamic modelling showed that the quantity of aggressive phases formed by released volatile fission products could be a critical parameter for Stress Corrosion cracking of zirconium based alloys in PWR [iii]. In order to improve the quality of this modelling we aim at determining how volatile fissions migrate during a power ramp.

On a theoretical point of view, the chemical phases formed when thermodynamic equilibrium is reached can be assessed by thermochemical modelling. But more kinetic data are needed to know when and where these equilibrium phases are actually made. A phase formed inside the nuclear ceramic as precipitates will be immobilised for a longer time than a phase formed outside the nuclear ceramic. There is, up to now, very little knowledge on the behaviour of volatile fission products, which are not gaseous inside the nuclear ceramic. This paper aims at study how volatile fission products behave inside a nuclear fuel submitted to a power transient. More specifically, the chemical phases formed by these volatile fission products in bubbles will be looked for. For that purpose a new experimental procedure was developed to measure the fission products inside a bubble formed during a power transient in a PWR fuel. 


\section{Experimental part}

\section{Sample history:}

A 4 meter long PWR fuel rod, with $4,89 \%{ }^{235} \mathrm{U}$ enriched $8.2 \mathrm{~mm}$ diameter pellets and $9.5 \mathrm{~mm}$ external diameter $0.57 \mathrm{~mm}$ thickness cladding in niobium doped zirconium based alloy, had been previously irradiated in a commercial reactor up to a burn-up of $36 \mathrm{GWd} / \mathrm{tU}$. The released gases were measured by puncturing after irradiation; they correspond to $0.5 \%$ of gas inventory. A $29 \mathrm{~cm}$ slice was cut from this rod and refabricated as a rodlet. This rodlet was irradiated in OSIRIS reactor. After a conditioning period at $196 \mathrm{~W} . \mathrm{cm}^{-1}$ during more than 18 hours, the power was raised up to $470 \mathrm{~W} . \mathrm{cm}^{-1}$ with a power increase around $100 \mathrm{~W} / \mathrm{cm}$.min and the rodlet was kept at this high power during 12 hours without any detected failure. The released gases during the power transient were measured by puncturing after irradiation; they correspond to $7 \%$ of gas inventory.

After power ramp, a slice was cut from the rodlet and prepared for post-test analysis. This slice was embedded in a metallic alloy to ensure the charges evacuation and polished perpendicular to the rodlet axis. The polished section is presented on Figure 1.
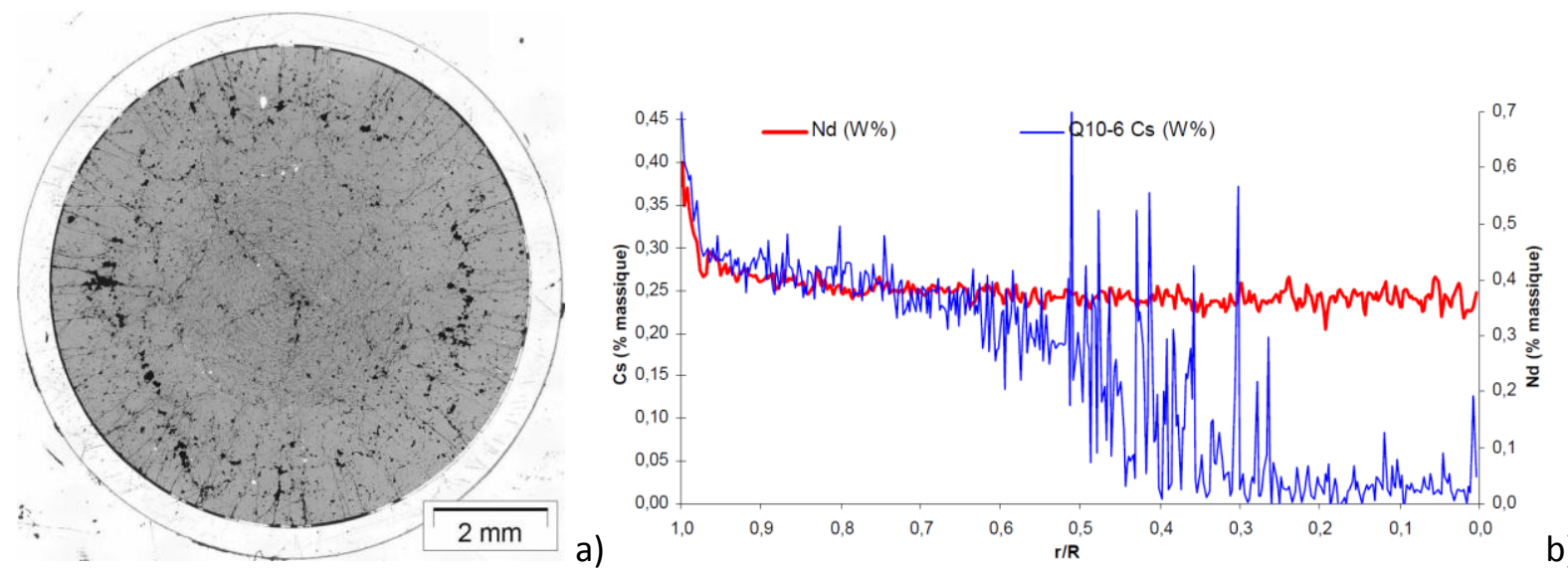

Figure1 : a)optical view of the analysed cross section $b) N d$ and Cs radial concentration profiles ( $r / R$ $=1$ at periphery, $r / R=0$ at pellet centre)

\section{Characterisation apparatus:}

This sample had been examined in the hot cells of the CEA LECA-STAR facility at Cadarache with:

- $\quad$ A shielded electron probe micro-analyser (EPMA) 'CAMECA' SX100R. [" ].

- $\quad$ SIMS [ $\left[{ }^{\mathrm{N}}\right]$

A first examination of the fuel evidenced that volatile fission products formed bigger precipitates in the centre of the pellet, consistently with the peak in Cs radial profile measured by EPMA (Figue1b). Consequently examination was focused in this area. Moreover EPMA mapping indicated that the precipitates containing volatile fission products would be located inside intragranular bubbles. This hypothesis was difficult to assess because bubbles opened during the sample polishing might have been filled with polishing dusts. Therefore it was necessary to analyse a bubble that had not been previously opened during sample preparation. We developed a dedicated procedure for that purpose that is described below. 
Procedure for analysing the Fission products with in one bubble:

First of all, EPMA Xe mapping was used to identify bubbles that were still filled with Xe fission gas underneath the sample surface. One bubble was then selected for further analysis. Its position is shown on Figure 2; though not opened it appears as a darker shadow on the electronic image. The sample was transferred to SIMS. SIMS mapping with low current primary beam was used to find out the selected bubble position. Then high current primary beam was focused at the bubble position while Xe signal was measured. The opening of the gas bubble was detected by a peak in the Xe signal, in a similar manner to [ $\left.{ }^{\mathrm{vi}}\right]$. New SIMS mapping with low current primary beam were then performed that confirmed the opening of the bubble and the presence of volatile fission products in it. The sample was transferred back to EPMA and EPMA mapping gave a qualitative composition of the phases that were contained in the bubble. No EPMA quantification was possible because the fission products within the bubble did not lie on a flat surface at a reference position.
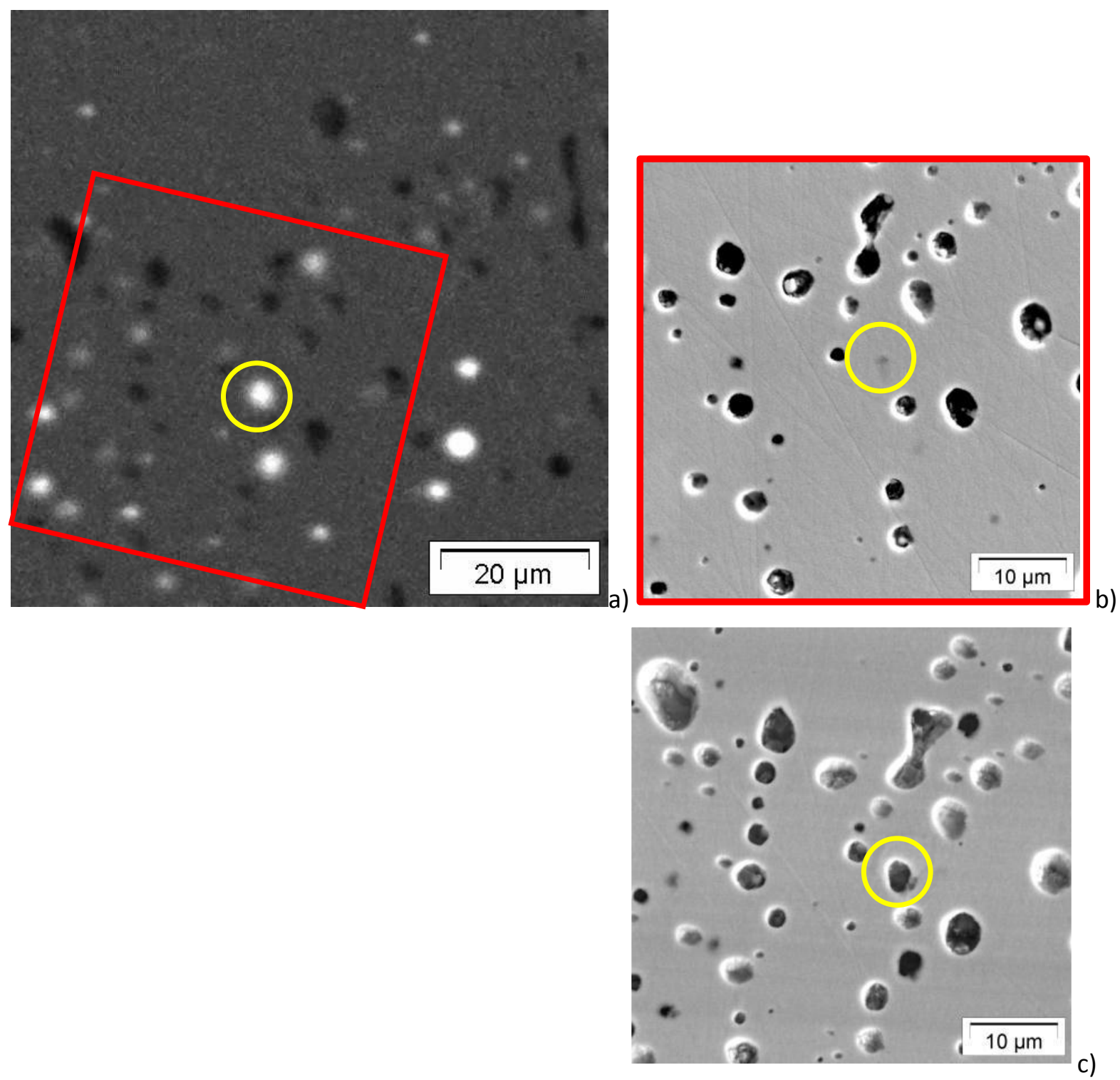

Figure 2: EMPA a) and Secondary electron images of the sample before b) and after c) sputtering. The bubble position lies inside the yellow circle. The red square in a) correspond to the image frame in b). 


\section{$\underline{\text { Results }}$}

The EPMA mappings of $\mathrm{Cs}, \mathrm{Te}, \mathrm{I}, \mathrm{Ba}, \mathrm{Ru}, \mathrm{Tc}, \mathrm{Mo}, \mathrm{Pd}$ and $\mathrm{Cr}$ of the opened bubble are presented on Figure 3. These fission products are characteristic of the volatile (Cs, I, Te) metallic (Mo, Ru, Tc) fission products according to Kleykamp's classification [iii]. $\mathrm{Cr}$ is a dopant added during fabrication. Ba has a specific status since it can be formed by decay of caesium. Hence it is impossible to state whether the barium observed in the bubble migrate towards the bubble as a barium atom or as a Cs atom that later decayed inside the bubble.

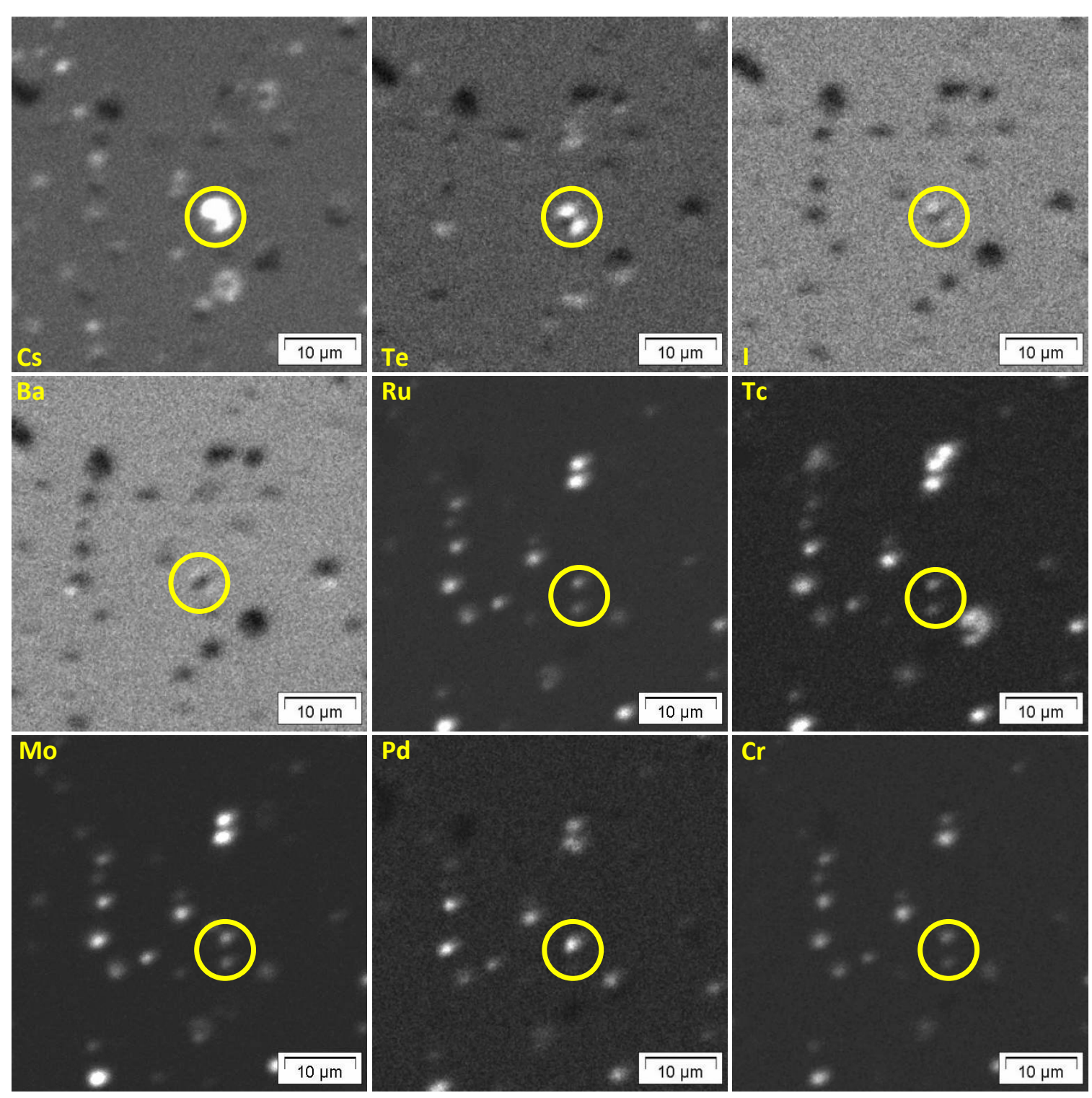

Figure 3: EMPA mapping of several fission products. The yellow circle corresponds to the bubbles identified in Figure 2.

The existence of these fission products in the bubble was also evidenced by EMPA before bubble opening and by SIMS after opening, but with a lower accuracy. In all images, the concentration of fission products outside bubbles is constant, giving a uniform colour on the mappings. EPMA mapping are not quantitative because the experimental background is not subtracted from the measured intensities. The actual concentration of Cs was measured by quantitative EMPA (Figure 
1b). These concentrations are near to zero within the experimental error bars. So in the central part of the pellet the fission products are either released out of the fuel or trapped in bubbles. Inside other bubbles, visible as darker area, some precipitates are observed or not. They could have not been observed for two main reasons: the precipitates could have been removed during polishing or they could be located at a too large depth.

\section{Discussion:}

The experimental results presented are now discussed to derive information on how volatile fission products behave at high temperature in ramped fuels.

Firstly, no new chemical phase is formed inside the fuel ceramic except within bubbles. No grey phase made of barium oxide as observed in FBR fuels [viii], no oxidised phase as observed the periphery of a ramped fuel $\left[{ }^{\mathrm{i}}\right]$, no caesium iodine or caesium molybdate precipitate (JOG) $\left.{ }^{\mathrm{x}}\right]$ could have been observed in the ceramic outside of the bubbles. This lead to the statement that thermodynamic equilibrium is not achieved within the fuel even though the centre of the pellet was subjected to a high temperature around $2000^{\circ} \mathrm{C}$. So the behaviour of the fission products must be considered in a kinetic point of view.

Secondly, the volatile fission products (Cs, I, Te) are in bubbles together with rare gazes, metallic fission products and the doping chromium. It is very unlikely that all these species converge to the same point to create at the same time a common precipitate. In FBR fuel metallic, barium zirconate type oxides and gas bubbles can be observed at different places [ $\left.{ }^{\mathrm{x}}\right]$. So we consider that a defect should exist first, on the surface of which the other fission products could nucleate with a heterogeneous precipitation mechanism. This precipitation mechanism might occur during in commercial operation or during the power transient or during both. The pre-existing defect could be an irradiation induced void as proposed in [ $\left.{ }^{\mathrm{xi}}\right]$ or a metallic aggregate (made of fission products and/or dopants) that are known to precipitate in reducing conditions in $\mathrm{UO}_{2}$ (see for example [xiii]). Whatever the first phase formed, the precipitation mechanism implies that the precipitated fission products were previously dissolved in the fuel matrix with a concentration higher than a solubility threshold and that they could diffuse in in the fuel ceramic. These requirements imply that, most probably, fission products are in mono-atomic state within $\mathrm{UO}_{2}$ crystalline structure. The solution energy of different fission products was calculated by first principle calculations [ ${ }^{\mathrm{xiv}}$ ]. These results predicted that some fission products precipitated and others did not; the calculated behaviour was in qualitative agreement with the observed behaviour of fission products. From this we conclude that the diffusion of fission products dissolved in monoatomic form are to be considered in order to describe the migration of fission products during a power transient.

Thirdly, the distribution of fission product is not uniform with the bubble. Two groups can be evidenced, metallic fission product and volatile fission products. The metallic fission products are located in two precipitates that are aligned along the vertical direction on Figure. The volatile fission products also form two precipitates by these latter are aligned more or less on a parallel direction of the diagonal of the mapping. This difference in location can be interpreted as a different physical and chemical behaviour of these compounds. First no phase associating volatile and metallic fission product seems to exist, such as caesium molybdate that would have put at the same location 
caesium and molybdenum. This can be justified by considering that oxygen potential at the pellet centre became more reductive. This point is developed elsewhere $\left[{ }^{x \vee}\right]$. Here we will simply consider that the chromium precipitation indicates oxygen potential, at which all metallic fission products should be in metallic phases. For such oxygen potential, the volatile fission products are expected to form Tel2, Csl, Te, Cs or CsTe2 chemical phases [ii].

These precipitates observed on EPMA mapping were also visible on secondary electron images (Figure 4). They are round-shaped, and one bubble can contain more than one precipitate. The round shape could be associated to a liquid phase that has been rapidly quenched, possibly liquid metallic fission products. Volatile fission products might have later condensed on the round precipitates from the gaseous phase to the liquid and solid phase. The shape of the bubbles that are not all rounded suggests that some bubbles could have coalesced during the power ramp. The existence of two metallic precipitates in the bubble that was analyzed is also consistent with this coalescence mechanism.

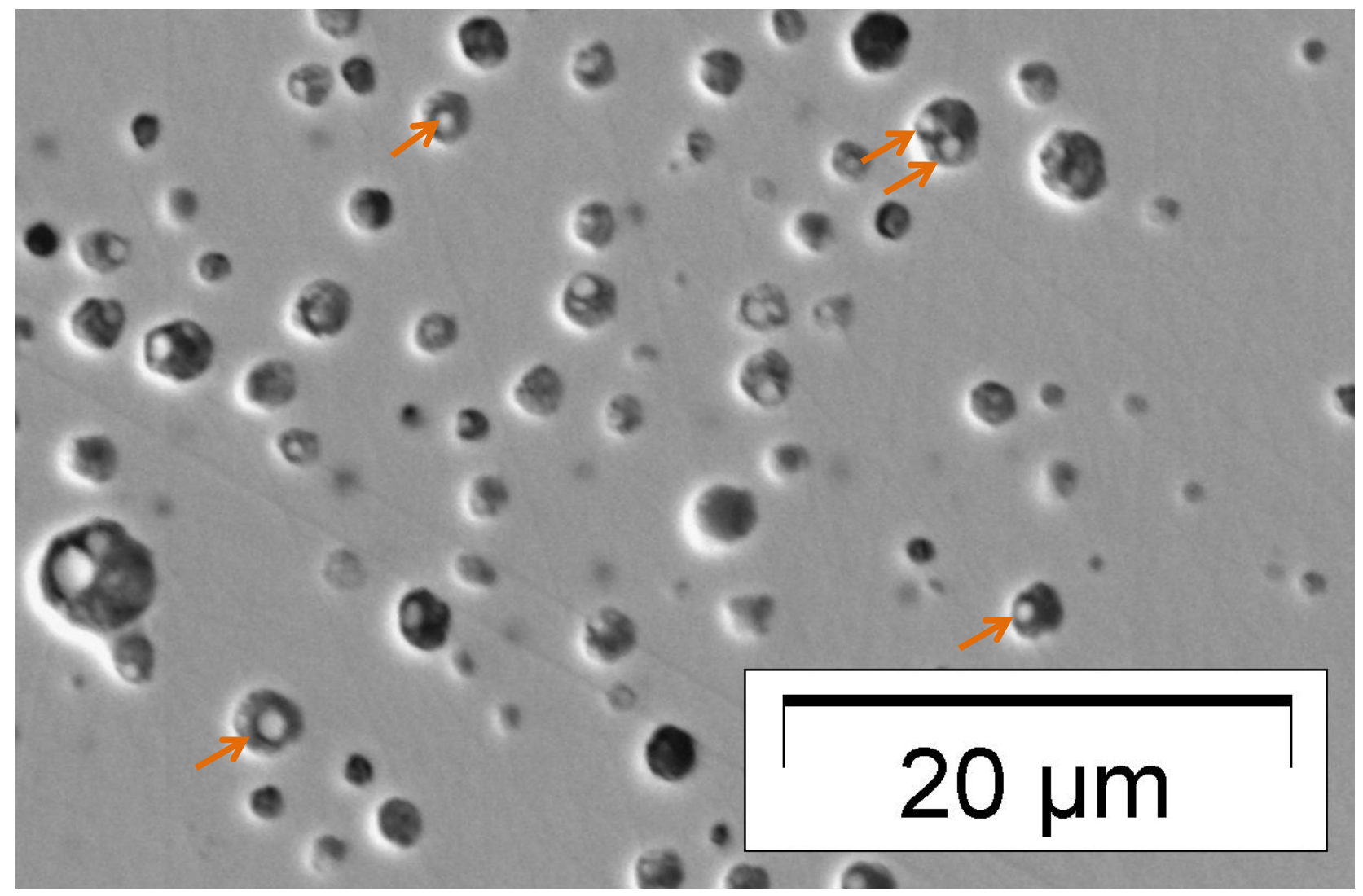

Figure 4 secondary electron image of the bubbles and the precipitates they contain (indicated by an arrow for some of them). 


\section{Conclusion:}

The results presented in this paper provided a new insight in the phenomenology of fission products during a power transient that can be divided in

- Insoluble fission products are likely to be in a monoatomic form dissolved in the nuclear ceramic.

- A defect, which could be could be an irradiation induced void or a metallic aggregate, would be more likely to precipitate first. This precipitation may occur during in commercial operation or during transient.

- The volatile and gaseous fission products would form bubbles by a heterogeneous mechanism at the surface of this defect.

- Inside the bubbles the fission products form chemical phases that correspond to the thermodynamic equilibrium conditions corresponding to the temperature and reductive oxygen potential they are submitted to.

- Two bubbles may coalesce during the power transient but their metallic fission products do not necessary coalesce.

- Metallic and volatile fission products form solid precipitates after quenching.

This phenomenology could be used for further modelling of the behavior of fission products during an incidental or accidental sequence.

Acknowledgements: The authors would like to thank EdF and AREVA for their financial support and fruitful discussions, and Laurence Noirot (CEA) for fruitful discussions.

\section{REFERENCES}

${ }^{\mathrm{i}}$ G.. Brillant, C. Marchetto, , W. Plumecocq, Annals Nucl. Ener. 61 (2013), 88-95

${ }^{i i}$ L. Desgranges, Ch. Riglet-Martial, I. Aubrun, et al., J. Nucl. Mater. 437 (2013) 409-414

${ }^{i i i}$ B. Baurens, J. Sercombe, C. Riglet-Martial, L. Desgranges, L. Trotignon, P. Maugis, J. Nucl. Mater. 452 (2014) 578-594

iv J. Lamontagne, Th. Blay, P. Navarra, 47th Annual meeting Working Group "Hot laboratories and remote handling”, Dimitrovgrad, Russia, 06-10 September 2010

${ }^{v}$ B. Rasser, L. Desgranges, B. Pasquet, Appl. Surf. Sci. 203-204 (2003) 673.

${ }^{\mathrm{vi}}$ J. Lamontagne, J. Noirot, L. Desgranges, Th. Blay, B. Pasquet , I. Roure Microchim. Acta, 145 (2004) 91

${ }^{\text {vii }}$ H. Kleykamp J. Nucl. Mater.131 (1985) 221-246

${ }^{\text {viii }}$ H. Kleykamp, J.O. Pashoal, R. Pejsa, F. Thommler, J. Nucl. Mat. 130 (1985) 426- 433.

${ }^{i x}$ L. Desgranges, J. Lamontagne, C. Riglet-Martial, Th. Blay J. Nucl. Mater. 457 (2015) 246-251

${ }^{x}$ K. Maeda, K. Tanaka, T. Asaga, H. Furuya, J. Nucl. Mater. 344 (2005) 274-280

${ }^{x i}$ M. Teague, B. Gorman, J. King, D. Porter, S. Hayes J. Nucl. Mater. 441 (2013) 267-273

xii Garcia, P.; Martin, G.; Sabathier, C.; et al. Nucl. Instrum. Methods B, 277 (2012) 98-108

${ }^{x i i i}$ Riglet-Martial, Ch.; Martin, Ph.; Testemale, D.; et al, J. Nucl. Mater. 447 (2014) 63-72

${ }^{\text {xiv }}$ G. Brillant F. Gupta, A. Pasturel, J. Nucl. Mater. 412 (2011) 170-176

${ }^{\mathrm{xv}}$ C. Martial submitted to JNM 